\title{
How to bridge the boundary? Determinants of inter-organizational social software usage
}

\author{
Melanie Steinhueser ${ }^{1}$ - Alexander Richter $^{2}$ • Stefan Smolnik ${ }^{3}$ \\ Received: 30 September 2013 / Accepted: 13 April 2015 / Published online: 10 May 2015 \\ (C) Institute of Information Management, University of St. Gallen 2015
}

\begin{abstract}
Based on their positive experiences with intraorganizational enterprise social software (ESS), the first organizations are currently deploying ESS in an interorganizational context. Nevertheless, hardly any research has addressed aspects pertaining to the commonalities of and differences between ESS and existing forms of interorganizational information systems (IOS). Following an information-processing view, and based on a systematic literature review, as well as on the results of an exploratory interview study, we propose a conceptual model of interorganizational ESS usage and relevant usage determinants. Some of these are known from prior studies, but have not yet been applied to an inter-organizational context (e.g., trust, knowledge sharing, security), whereas others were newly identified in our interview study (e.g., confidentiality, productiveness, dynamics). The proposed model extends the current understanding of IOS and helps address the field of interorganizational ESS usage more appropriately in theory and practice.
\end{abstract}

Responsible Editors: Holger Schrödl and Ali Sunyaev

Melanie Steinhueser

melanie.steinhueser@uos.de

Alexander Richter

arichter@ifi.uzh.ch

Stefan Smolnik

stefan.smolnik@fernuni-hagen.de

1 Institute of Information Management and Information Systems Engineering, Osnabrück University, Katharinenstraße 1, 49069 Osnabrück, Germany

2 Department of Informatics, University of Zurich, Binzmuehlestrasse 14, 8050 Zürich, Switzerland

3 Faculty of Business Administration and Economics, University of Hagen, 58084 Hagen, Germany
Keywords Social software · IOS $2.0 \cdot$ Enterprise $2.0 \cdot$ IS usage $\cdot$ Conceptual model $\cdot$ Interview study

\section{JEL Classification 033}

\section{Introduction}

Although the corporate realm's adoption of social software lags behind that of private households, many organizations have become interested in such applications over the years. For example, a recent report claims that $72 \%$ of more than 4 , 200 globally acting companies have adopted at least one social software (Bughin et al. 2011). Several other studies have shown that enterprise social software (ESS) can be used to support, for example, communication, knowledge management, and innovation management (Faraj et al. 2011; Kane et al. 2009; Trier and Richter 2014). Furthermore, companies have experienced considerable changes in the way they communicate, collaborate, and coordinate internally once they have implemented ESS (Aral et al. 2013; Riemer et al. 2009). Whereas the capacity to deal with such applications and technologies is maturing slowly (Kiron et al. 2013), companies are increasingly realizing benefits and competitive advantages from using ESS internally, such as improved productivity, better knowledge sharing (Chui et al. 2012), and enhanced employee innovativeness (Gray et al. 2011).

Having gathered experiences with ESS usage in an intraorganizational context, a reasonable next step would be for organizations to expand such applications to business-tobusiness scenarios. Nevertheless, the question of how to transfer these potentials beyond the organizational border, i.e., how ESS can be used inter-organizationally, remains largely unanswered (Jussila et al. 2013). Although organizations have gained experiences with various inter-organizational information 
systems (IOS) during the last 50 years, they nevertheless seem reluctant to use ESS in this context. Accordingly, very little research synthesizes the commonalities of and differences between ESS and the existing IOS forms (Schlagwein et al. 2011).

The purpose of our study is therefore to gain a better understanding of ESS usage in inter-organizational partnerships. Consequently, we will address the following research questions: What are the relevant usage determinants to consider when applying ESS inter-organizationally? Do they differ from the usage determinants of other forms of IOS? Do they differ from the intra-organizational usage of ESS? If so, what are these differences? Answers to these questions can help companies better understand the usage determinants of interorganizational ESS that could promote the partnership performance and also guide future activities in this new research field.

Figure 1 illustrates the framework that informed our research process. We carried out a structured literature review and an exploratory interview study. The literature review first shows that there is a lack of research on ESS used in an inter-organizational context and, thus, motivates our study. It furthermore provides us with a comprehensive overview of the state-of-the-art of ESS research. An established IOS model (Bensaou and Venkatraman 1993) helps us structure the literature review's results, which serve as a basis and preparation for the subsequent data collection. Based on an exploratory interview study, we adapt and extend the existing model to reflect the ESS-specific usage determinants. Together, our results help us develop a rich picture of the determinants of inter-organizational ESS usage. They not only provide a framework for future research, but can also help project leaders better understand ESS usage and its possible coordination mechanisms in an inter-organizational setting.

The next section describes the theoretical foundations of both inter-organizational information systems and enterprise social software. It presents the results of our literature review of previous ESS research, and provides us with findings that could be transferred to our research's context. In the subsequent section, we outline our approach to collecting explorative empirical data and to analyzing this data. In the findings section, we use empirical evidence to further develop our conceptual model of inter-organizational ESS usage. The discussion section summarizes the results, while the conclusions section outlines our research's contributions, implications, and limitations.

\section{Theoretical foundations}

\section{Inter-organizational information systems}

An inter-organizational information system can be understood as "an automated information system shared by two or more companies" (Cash and Konsynski 1985, p. 134). It allows information to be sent across organizational boundaries and allows shared access to stored data and applications (Johnston and Vitale 1988). IOS research originated about 50 years ago. As early as 1966, Kaufman recognized IOS's impact on the way business is conducted when time-sharing services and online databases are analyzed. Czepiel (1975), one of the first to do so, described the patterns of inter-organizational communications and the diffusion of a major technological innovation. Based on these early publications, the 1980s produced a great deal of conceptual work in the IOS field. Patterns were identified and the first IOS typologies developed. Barrett and Konsynski (1982), for example, proposed a five-level typology based on the intensity of a firm's IOS participation. In another article, Barrett (1986) discussed a range of strategic options and IOS implementations. She demonstrated that an IOS can be a powerful strategic tool, a means of establishing control within a distribution chain, and can have an industrywide scope, or can be a traditional information system (IS) built around independently owned units.

After meeting the United Nations' EDIFACT standard and spurred by the Internet's rapid diffusion, companies further deepened their computer-mediated relationships. In the following years, research in the IOS field has been characterized by its increasing maturity. IOS's interdependencies and success factors, as well as its risks and possible outcomes, have been increasingly studied as IOS implementations have matured in companies. Whereas Riggins and Mukhopadhyay (1994), for example, examine the benefits of IOS, Kumar and Van Dissel (1996) identify the possible risks and suggest strategies for minimizing the likelihood of such risks. Later, researchers (e.g., Lu et al. 2006; Soliman and Janz 2004; Mouzakitis and Askounis 2010) focus on further developing and deepening our knowledge of critical success factors, or on discussing problems in the IOS field (e.g., Goethals 2008). Ibbott and O'Keefe (2004), for example, show that trust and the nature of the inter-firm relationship are more important than the approach to IOS development. Similarly, Gallivan and Depledge (2003) examine the roles of trust and control
Fig. 1 Research process

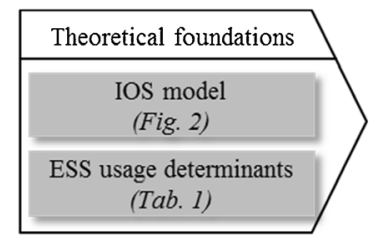

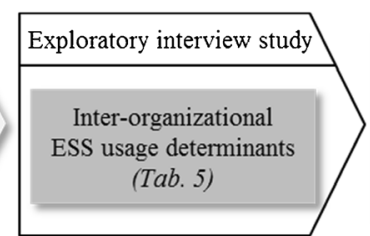

Model of inter-organizational ESS usage (Fig. 4) 
in IOS partnerships. Furthermore, several researchers address strategic questions (e.g., Choudhury 1997; Hagedoorn 1993; Rai and Tang 2010) and integration issues (e.g., Giachetti 2004; Saeed et al. 2011; Schubert and Legner 2011; Stelzer et al. 2006).

As described above, single impact factors have often served as the object of analysis. In contrast, Bensaou and Venkatraman (1993, 1995 and 1996) have developed a comprehensive model to guide IOS research. Their model is rooted in the intra-organizational information-processing view (Galbraith 1977) and has been extended to an interorganizational level of analysis. The information-processing view allows for integrating different perspectives applied to IT-mediated relationships. The model is assumed to provide insights into the usage determinants and implications of different strategies for inter-organizational coordination (see Fig. 2). Bensaou and Venkatraman propose that the information-processing needs arising from uncertainty should fit the information-processing capabilities derived from a number of mechanisms for organizational coordination and, thus, lead to a high performance.

Although researchers have moved from individual, clearcut visions of simple corporate programs to recognize the complexity of alliances and networks (Osborn and Hagedoorn 1997), the research results generated by the first wave of IOS research are not one-to-one transferrable to the next generations of IOS, which are based on the Internet and XML technologies' open standards (Robey et al. 2008). Progress in terms of capabilities and features, as well as changes in inter-organizational cooperation, needs to be considered in future research. Single papers have addressed this issue, such as that of Löhe and Legner (2010), who seek to improve our fundamental understanding of how serviceoriented architectures (SOAs) are applied in business networks and how they differ from other forms of IOS.

In conclusion, IOS is a mature research stream. However, since technologies have become more sophisticated, and the way companies communicate and collaborate across organizational boundaries has changed over time, the emergence of ESS should lead to a verifying of previous research results.

\section{Enterprise social software}

Although it is difficult to draw a clear line between ESS and other types of IS (Kane et al. 2014), there are some characteristics which distinguish them from each other. Potentially, these distinguishing characteristics require researchers to adapt established theories, or possibly develop new ones (Majchrzak 2009). As a working definition, we refer to ESS as web-based technologies that support users' contribution of persistent objects to a shared pool and that enable public responses to these objects. ESS comprises functionalities that visualize profile information and link users with one another (e.g., discover/subscribe/follow/friend). ESS could, for example, be weblogs, wikis, microblogs, or social networking platforms covering various applications. However, the mentioned characteristics provide an abstract interpretation; accordingly, we do not limit our understanding to particular applications, but adopt a broad view that includes all of the types that these traits cover.

In contrast to the relatively mature domain of IOS, research on ESS is quite new. The first studies focused on analyzing single applications, rather than on comprehensive ESS platforms, which are increasingly used today. These studies often either explored the potential of different applications like wikis (Pfaff and Hasan 2007), weblogs (Du and Wagner 2006), microblogs (Riemer and Richter 2010), and social bookmarking (Damianos et al. 2007), or focused on their success factors. Recent publications still reveal interesting insight into the potential of single applications (see, e.g., Majchrzak et al. 2013; Papadopoulos et al. 2013). However, as the maturity level of companies' ESS implementations increases, researchers increasingly focus on exploring and analyzing integrated ESS platforms. Wu (2013), for example, has found that information-rich networks, enabled by ESS, have a positive effect on various work outcomes such as productivity. Authors are also increasingly concerned with strategic issues. Duane and OReilly (2012), for example, propose a conceptual "stages of growth" model for managing an organization's ESS business profile. von Krogh (2012) states that using ESS for knowledge management changes the way employees and firms create and distribute data, information, and
Fig. 2 Model of interorganizational relationships (Bensaou and Venkatraman 1993)

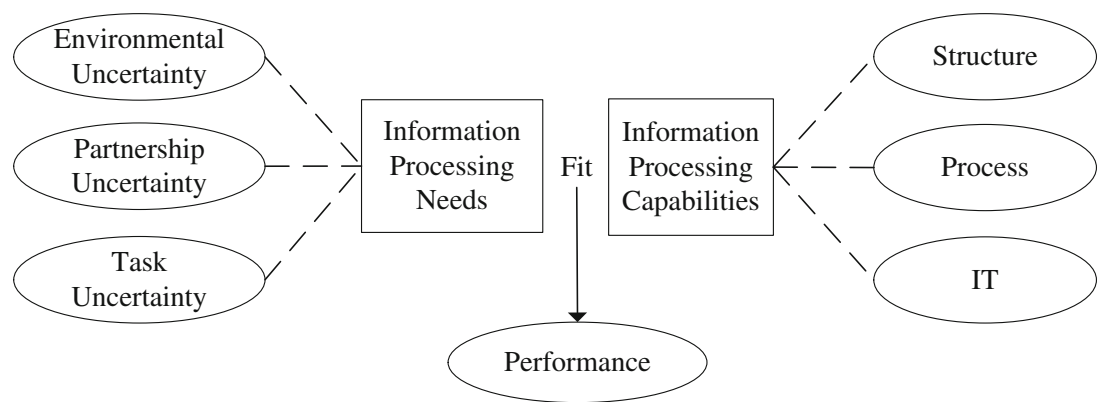


knowledge. He discusses the ways the value of the firm's internal knowledge can be ensured, although ESS increasingly enables content from outside the firm to be used cost-free and flexibly.

von Krogh (2012) is not the only author to discuss organizational boundaries in the context of ESS usage. In a comprehensive literature review, Schlagwein et al. (2011) classify research in the field of ESS into the following three communication scenarios: (1) users only (user co-creation), (2) employees and users (R\&D, production, marketing), and (3) employees only (firm-internal knowledge sharing). But publications explicitly devoted to the inter-organizational usage of ESS are not mentioned in this study. In their recent work, Huang and Güney (2012) find four relationships of ESS usage. One of these is labeled "inter-organization." However, the authors use their classification scheme to develop a framework of socialsoftware-driven organizational learning and do not explicitly examine the inter-organizational type of relation.

Very few publications explicitly examine the interorganizational usage of ESS. Gonzalez (2013), for example, states that ESS can and should play a central role in supply chain management (SCM). He explains that ESS supports SCM communication and collaboration, and provides examples of this. Similarly, O'Leary (2011) investigates the current and potential impact that ESS's capabilities have and may have on the supply chain; the focus is on public social networks such as Facebook and Twitter. Jussila et al. (2013), who survey ESS use cases, opportunities, and challenges in industrial business-to-business companies, take another perspective. All of these authors' articles provide valuable information gained from surveys, but they do not attempt to develop a theory-driven knowledge base.

In order to draw valid and traceable implications from previous research on ESS regarding its usage in an interorganizational context, we conducted an extensive literature review, following a structured approach as Webster and Watson (2002) propose. We searched leading IS journals to identify relevant articles, using the keyword sieves that the online databases EBSCO and IEEE Xplore, the ACM Digital Library, and Google Scholar offer. The meaning and significance of system usage in IS research has been a matter of controversy (DeLone and McLean 2003; Gelderman 1998; Yuthas and Young 1998). Usage can be seen as causing a system's success and as an appropriate measure of this success (DeLone and McLean 1992). However, it has also been argued that usage precedes performance and, thus, success (Seddon 1997). Consequently, we did not limit our search to a specific usage term, but took a broader perspective and included related constructs such as "adoption," "use," "success," and "performance." Our search also covered the terms "social software," "social media," "social computing," and "social networking." ICIS, ECIS, and HICSS conference proceedings were also considered in order to complete the list of articles. This search resulted in 67 publications. After reviewing the abstracts for relevance, we excluded 23 articles as not focusing on the identification of ESS's usage determinants. We found that a large proportion of the remaining articles adopted a marketing perspective (e.g., Goh et al. 2013), or focused on the private usage of online social networks such as Facebook or Twitter (e.g., Koroleva et al. 2011). We therefore limited our analysis to studies focusing on ESS usage in an "employees only" setting (refer to previous section) and, thus, excluded papers on communication scenarios with private users for user co-creation or marketing purposes (see Schlagwein et al. 2011). This left us with 25 articles. By applying forward and reverse searches, we found two more relevant articles, eventually resulting in 27 articles for our study. Table 1 provides an overview of these publications in chronological order, with the identified usage determinants noted in the last column.

\section{Classification of ESS usage determinants in the IOS context}

As our intention was to study the ESS usage determinants that eventually lead to a better partnership performance, we drew upon the inter-organizational relationships' model (Bensaou and Venkatraman 1993) and classified those determinants identified in prior ESS research (as given in Table 1) into the proposed dimensions. To this end, we consulted Mayring's (2000) deductive category application, working with predefined and theory-based aspects of analysis, which we describe in the following. Since information processing needs arise from different types of uncertainty, we assigned determinants referring to uncertainty to that dimension. On the other hand, we classified determinants referring to mechanisms for organizational coordination into the information processing capabilities dimension. The three authors of this paper undertook the classification process. Doubts were discussed until clarification was reached. Table 2 presents the outcome of this classification process, i.e., the determinants of intra-organizational ESS usage assigned to IOS dimensions. To ensure the classification's transparency, sample references support each determinant.

It became apparent that many determinants concerning organizations' information-processing capabilities have been researched in the context of internal ESS usage. Many of these determinants could be classified into the originally proposed categories (structure, process, IT). Technological features, such as integration and customization, for example, fit into the IT category. However, there are also determinants that play a crucial role, but are difficult to classify into one of the existing categories, for example, different cultural parameters like openness and the communication environment. In comparison, the information-processing needs dimension produces fewer research results. This is hardly surprising, since uncertainties specifically arise in partnerships and do not play such a crucial role when ESS is used in an internal context. Nevertheless, some studies have educed determinants, for 
Table 1 Determinants of intra-organizational ESS usage

\begin{tabular}{|c|c|c|c|c|}
\hline Authors & Year & Objects & Outcome & Identified Determinants \\
\hline Du \& Wagner & 2006 & Weblogs & Success & Technological features \\
\hline Pfaff \& Hasan & 2007 & Wikis & $\begin{array}{l}\text { Performance, learning, } \\
\text { knowledge store, } \\
\text { innovation }\end{array}$ & $\begin{array}{l}\text { Technical (maintain) } \\
\text { Management (training, motivation; rewards) } \\
\text { Culture (mutual trust and influence) } \\
\text { Social (recognize, understand, and value) } \\
\text { Legal (monitor content) }\end{array}$ \\
\hline Scott \& Hester & 2007 & Wikis & $\begin{array}{l}\text { Collaboration, knowledge } \\
\text { sharing }\end{array}$ & $\begin{array}{l}\text { Facilitators: suitability for the task and technology, } \\
\text { motivation, training } \\
\text { Deterrents: cultural hurdles of hierarchy, reluctance } \\
\text { to share knowledge, resistance to change }\end{array}$ \\
\hline Hester \& Scott & 2008 & Wikis & Adoption and diffusion & $\begin{array}{l}\text { Organizational culture, organizational compatibility, } \\
\text { relative advantage, complexity, critical mass }\end{array}$ \\
\hline Hsu \& Lin & 2008 & Weblogs & Intention to blog & TAM factors, knowledge sharing, and social influences \\
\hline Trimi \& Galanxhi-Janaqui & 2008 & Weblogs & Acceptance and success & $\begin{array}{l}\text { Congruence between the organization's and users' } \\
\text { benefits from blogs }\end{array}$ \\
\hline Prasarnphanich \& Wagner & 2009 & Wikis & Success & Technology, participant motivations, altruism \\
\hline Theotokis \& Doukidis & 2009 & ESS & Acceptance & $\begin{array}{l}\text { Rate and variety of use, user stickiness, and addiction } \\
\text { tendency }\end{array}$ \\
\hline Wattal et al. & 2009 & Weblogs & Adoption & Age, managerial influence \\
\hline Chai \& Kim & 2010 & Weblogs & Knowledge sharing & Trust \\
\hline Räth \& Smolnik & 2010 & Weblogs & Benefits & $\begin{array}{l}\text { Social (peer groups), individual (perceived benefits), } \\
\text { organizational (control, trust, organizational culture, } \\
\text { management support) }\end{array}$ \\
\hline Seo \& Rietsema & 2010 & ESS & Moving toward Enterprise 2.0 & $\begin{array}{l}\text { Organizational structure, organizational culture, } \\
\text { communication environment, leadership }\end{array}$ \\
\hline Wattal et al. & 2010 & Weblogs & Usage & Network effects (others' actual usage, positive feedback) \\
\hline Gray et al. & 2011 & Social bookmarking & Employee innovativeness & Social diversity of information sources \\
\hline Hsu \& Tsou & 2011 & Weblogs & Purchase intention & Information credibility, customer experiences \\
\hline Steinhueser et al. & 2011 & ESS & Success & $\begin{array}{l}\text { System quality (integration, customization, flexibility) } \\
\text { Information quality (content accuracy, understandability) } \\
\text { Enterprise } 2.0 \text { readiness (communication } \\
\text { culture, provided resources, individual traits) }\end{array}$ \\
\hline Turban \& Liang & 2011 & ESS & Success & $\begin{array}{l}\text { Economic: feasibility, justification } \\
\text { IT infrastructure: readiness, security, risks } \\
\text { Organization: readiness, privacy, support, culture, } \\
\text { resistance to change, legal }\end{array}$ \\
\hline Chai \& Kim & 2012 & ESS & $\begin{array}{l}\text { Knowledge } \\
\text { contribution behavior }\end{array}$ & Ethical culture; social ties, sense of belonging \\
\hline Kügler et al. & 2012 & ESS & Usage & $\begin{array}{l}\text { Technological factors (relative advantage, ease of use, } \\
\text { result demonstrability, compatibility) } \\
\text { Social factors (reputation, perceived critical mass) } \\
\text { Organizational climate (trust, collaboration norms, } \\
\text { community identification) }\end{array}$ \\
\hline Räth et al. & 2012 & ESS & Success & $\begin{array}{l}\text { Communication of usefulness, starting with champions, } \\
\text { top management support and involving training of, and } \\
\text { communicating with users, start-up content; corporate } \\
\text { culture }\end{array}$ \\
\hline Saldanha \& Krishnan & 2012 & ESS & Adoption & $\begin{array}{l}\text { Importance of open standards; size of organization, } \\
\text { industry knowledge intensity }\end{array}$ \\
\hline Kügler \& Smolnik & 2013 & ESS & Individual benefits & Usage \\
\hline Majchrzak et al. & 2013 & Wiki & Knowledge reuse & Shaping \\
\hline Papadopoulos & 2013 & Weblogs & Knowledge sharing & $\begin{array}{l}\text { Self-efficacy, perceived enjoyment, certain personal } \\
\text { outcome expectations, and individual attitudes }\end{array}$ \\
\hline Richter \& Riemer & 2013 & ESS & Adoption & Malleability \\
\hline Trier \& Richter & 2013 & ESS & Adoption & Simplicity \\
\hline $\mathrm{Wu}$ & 2013 & ESS & Productivity and job security & Social network effects \\
\hline
\end{tabular}


Table 2 Determinants of intra-organizational ESS usage classified into IOS dimensions

\begin{tabular}{|c|c|c|c|}
\hline \multicolumn{2}{|c|}{ Information Processing Needs } & \multicolumn{2}{|l|}{ Information Processing Capabilities } \\
\hline Determinants & Sample Reference & Determinants & Sample Reference \\
\hline $\begin{array}{l}\text { Trust } \\
\text { Influence }\end{array}$ & $\begin{array}{l}\text { Chai and Kim } 2010 \\
\text { Pfaff and Hasan } 2007\end{array}$ & $\begin{array}{l}\text { Technological features (integration, customization, } \\
\text { flexibility, simplicity, malleability, security) }\end{array}$ & Du and Wagner 2006 \\
\hline Control & Räth and Smolnik 2010 & & \\
\hline \multirow[t]{2}{*}{ Compatibility } & Kügler et al. 2012 & Management (training, motivation, leadership) & Pfaff and Hasan 2007 \\
\hline & & $\begin{array}{l}\text { Culture (knowledge sharing, openness, communication } \\
\text { environment) }\end{array}$ & Turban et al. 2011 \\
\hline Task technology fit & Scott and Hester 2007 & Organizational structure & Seo and Rietsema 2010 \\
\hline
\end{tabular}

example, control and trust (e.g., Chai and Kim 2010) that affect uncertainties in a partnership, and can thus be classified accordingly.

After we had reviewed previous research, the following questions arose: To what extent can the determinants regarding the internal usage of ESS, which were deduced from prior research, be transferred to an inter-organizational context? What are the differences between using ESS across organizational boundaries rather than in an intra-organizational context? Our study addresses these questions. Furthermore, using an explorative research approach, we aim at revealing the determinants that neither prior research on IOS, nor that on ESS, has explained.

\section{Data collection and analysis}

Given that theoretical insights and practical experience with inter-organizational ESS are still limited, our primary goal is to contribute to a better understanding of the determinants that impact the appropriateness of ESS usage. We are particularly interested in analyzing how these determinants differ from those we have seen in prior IOS forms and from ESS's internal usage. Since theory is a good guide to data collection and one of the ways in which data can be analyzed (Walsham 2006), we consulted the inter-organizational relationships model (Bensaou and Venkatraman 1993) described above. We used this model as a framework for and as the starting point of our empirical research. Owing to the weak empirical basis in the field, we selected an explorative qualitative research method based on semi-structured interviews (Schultze and Avital 2011). This allowed for considering determinants that the underlying model does not cover (Dubé and Paré 2003), and for making exploratory assessments of the relevant determinants (Spencer and Britain 2003).

Prior to conducting the interviews, we developed an interview guideline to support our conversation with the interviewees (Bryman and Bell 2007). Keeping the interorganizational relationships model in mind, we questioned the participants about their need to use ESS and the capabilities that lead to its successful usage. If the interviewees did not mention this spontaneously, we asked them about the specific determinants we had gained from our prior research on ESS such as the role of organizational culture. Hence, the interview guide contained general questions about the scenarios of interorganizational software usage and about the reasons for using ESS (instead of, e.g., email). This allowed for comparing the interviews, while simultaneously leaving sufficient room for comprehensive statements and additional questions. We designed our interview questions by capturing the different aspects of various ESS applications on a meta-level, which abstracts from individual functions and implementation details, and reflects the use cases of such applications. Figure 3 provides an excerpt from the interview guide.

Data collection took place between July and September 2013. Two researchers conducted eight telephone interviews.
Fig. 3 Excerpt from the interview guideline
- General information on the interviewee, position in organization, and organization.

- Experience with intra- and inter-organizational ESS. (Where necessary, establish a mutual understanding of the term "ESS".)

- Use cases of inter-organizational ESS:

- Why is it used?

- How is it used?

- What kind of tool(s) is (are) used?

- Who uses it?

- What determinants are relevant for inter-organizational ESS usage (e.g., concerning culture, IT, structure)?

- What kind of benefits and risks arise?

- Have negotiation processes between the involved parties taken place? If so, which aspects have they covered? 
Owing to the early state of inter-organizational ESS implementations, we were glad to find competent interviewees, who had been deeply involved in projects in which ESS platforms are used inter-organizationally. All of these platforms include various applications, such as networking functionalities, wikis, and (micro-) blogs. Table 3 provides an overview of the sample.

During the interviews, we adopted the role of neutral observers (Walsham 2006). Although we know this does not mean that we were unbiased, we endeavored to obtain as frank as possible answers from different perspectives. The interviews lasted between 30 and $50 \mathrm{~min}$. The interviewers recorded, transcribed, and independently encoded the answers of the respondents. Each of the text documents underwent a qualitative content analysis (Mayring 2000). Thereby, we used a semi-directed approach by consulting existing theory (the model of inter-organizational relationships) and prior research on ESS (as given in Table 2) to deductively build a coding scheme (Potter and Levine-Donnerstein 1999), as well as apply an inductive categorization approach.

We reduced the transcribed interviews to short paraphrases, isolating a total of 221 . We subsequently deduced these paraphrases' relevant parameters by means of deductive category application (Mayring 2000): In a first step, we applied the original model's parameters. Where this was impossible, we consulted prior research on ESS (as given in Table 2) and extended the model. We inductively gave any text that could not be categorized with these predetermined codes a new one from the material (Mayring 2000). Each researcher assigned the identified parameters - where possible - to the interorganizational relationships model's categories. Finally, after presenting the coding results to the research group, problematic issues were resolved through discussion. Table 4 shows three examples of our applied coding procedure.

In terms of our research's quality criteria, we refer to Dubé and Paré (2003), who summarize and discuss evaluation attributes. Since subjectivity was important in our research's cognitive process, we involved a team of researchers in the data collection and analysis to provide intersubjectivity. We aim at providing reproducibility and, thus, at meeting reliability demands through the team-based research, as well as through the data collection and analysis processes' elucidation. The search for cross-case patterns and a comparison of our findings with the extant literature ensure the research's validity.

\section{Findings}

\section{Overview}

In our interview study, we identified 19 parameters that are relevant for inter-organizational ESS usage. Table 5 shows the determinants and their occurrences in the interviews - denoted

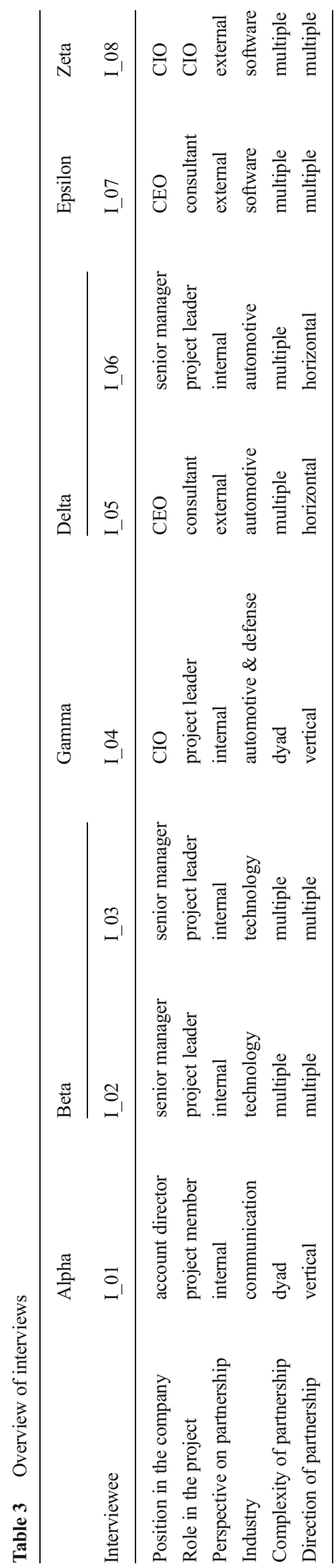


Table 4 Examples of the coding procedure

\begin{tabular}{|c|c|c|c|c|}
\hline \multicolumn{2}{|l|}{ Identification of determinants } & \multicolumn{3}{|c|}{ Classification of determinants } \\
\hline Citation & Paraphrase & Parameter $>>$ & Category & Dimension \\
\hline $\begin{array}{l}\text { "Hierarchies don't become superfluous. But they have to be } \\
\text { more dynamic and faster." }\end{array}$ & Hierarchy has to be dynamic. & Dynamics & Structure & Capabilities \\
\hline $\begin{array}{l}\text { "For us it is of highest importance to know where the } \\
\text { information lies and who is responsible for its } \\
\text { protection." }\end{array}$ & $\begin{array}{l}\text { Data location and } \\
\text { esponsibility are important. }\end{array}$ & Security & IT & Capabilities \\
\hline $\begin{array}{l}\text { "We use the platform for knowledge exchange and } \\
\text { mutual work on projects." }\end{array}$ & $\begin{array}{l}\text { Platform is used for mutual } \\
\text { content creation. }\end{array}$ & Productiveness & Task Uncertainty & Needs \\
\hline
\end{tabular}

by a "+". Following the information-processing view, we assigned these parameters into the categories that Bensaou and Venkatraman (1993) propose.

We found ten parameters that could be classified into the capabilities dimension's existing categories. The needs dimension covers six parameters. We also identified three parameters that we were unable to assign to the existing categories, which we labeled not classifiable - see Table 5.

Our interviews provided little evidence of the importance of environmental uncertainty. Only one interviewee mentioned the impact that a competitive environment and its degree of stability have on the need to use ESS. The other interviews did not reveal the relevance of this category at all, which may be due to the interviewees having an IT background rather than a strategic one. In contrast, two different partnership uncertainty parameters play an important role in the settings that the interviewees described. In these, the roles of trust and the power-dependence balance are of particular relevance. Three parameters are incorporated into the task uncertainty category. Confidentiality's extreme relevance deserves particular attention. Furthermore, the extent to which a task is productive (in contrast to a more conversational action) plays a crucial role.

All the coordination mechanisms in the capabilities dimension, as proposed by the original model of inter-organizational relationships, can be adapted to an ESS context. Since this dimension incorporates usage determinants that lead to a high performance when coordinated appropriately, many of the parameters are, unsurprisingly, well-known from prior research on ESS. For example, integration's relevance was mentioned in almost every interview.

Table 5 Results

\begin{tabular}{|c|c|c|c|c|c|c|c|c|c|c|}
\hline \multicolumn{3}{|l|}{ Determinants } & \multicolumn{8}{|c|}{ Mentions in interviews } \\
\hline Dimension & Category & Parameter & I_01 & I_02 & I_03 & I_04 & I_05 & I_06 & I_07 & I_08 \\
\hline \multirow{6}{*}{$\begin{array}{l}\text { Information processing } \\
\text { needs }\end{array}$} & \multirow[t]{2}{*}{ Partnership uncertainty } & Trust & & & + & & & + & + & + \\
\hline & & Power & & + & + & & & & + & \\
\hline & \multirow[t]{2}{*}{ Task uncertainty } & Confidentiality & + & & + & + & + & + & & + \\
\hline & & Productiveness & + & + & & & + & + & & \\
\hline & \multirow[t]{2}{*}{ Environmental uncertainty } & Competitiveness & & & & & + & & & \\
\hline & & Stability & & & & & + & & & \\
\hline \multirow{13}{*}{$\begin{array}{l}\text { Information processing } \\
\text { capabilities }\end{array}$} & \multirow[t]{3}{*}{ Structure } & Dynamics & + & & & + & + & + & & + \\
\hline & & Transparency & & & & + & + & + & & \\
\hline & & Resources & & & + & + & + & + & & \\
\hline & \multirow[t]{3}{*}{ Process } & Alignment & + & + & & + & + & + & + & + \\
\hline & & Privacy & & + & + & + & + & + & & \\
\hline & & Support & & & + & + & + & + & & \\
\hline & \multirow[t]{4}{*}{ IT } & Usability & + & + & + & + & + & & & + \\
\hline & & Malleability & & + & & & + & + & + & + \\
\hline & & Integration & + & + & + & + & + & + & & + \\
\hline & & Security & & + & + & + & + & + & + & + \\
\hline & \multirow[t]{3}{*}{ Not classifiable } & Open mindedness & + & & & + & + & + & & + \\
\hline & & Knowledge sharing & & + & + & + & + & + & & + \\
\hline & & Awareness & + & & & + & + & + & + & + \\
\hline
\end{tabular}


Fig. 4 Model of interorganizational social software usage

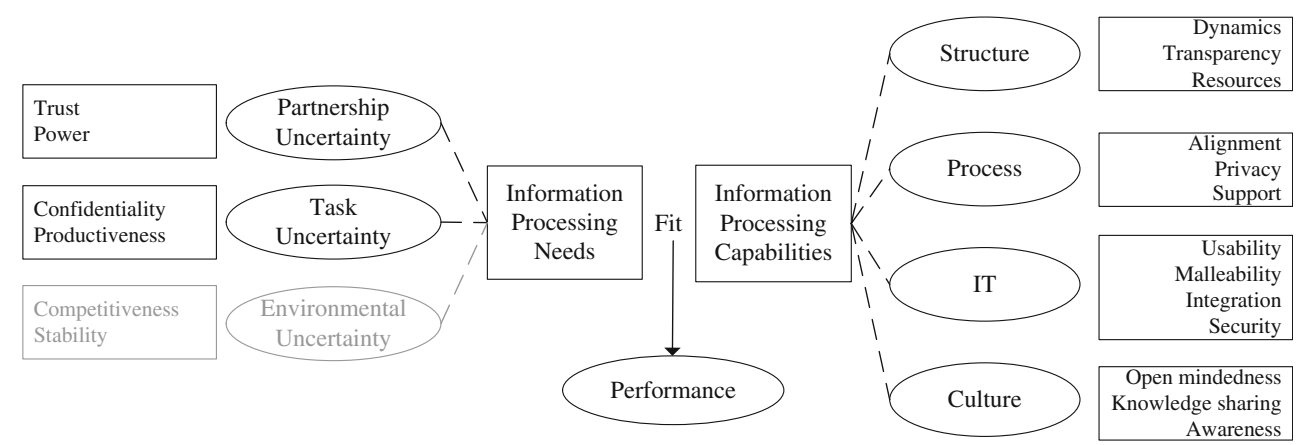

We identified three parameters that the original model's categories do not cover: open mindedness, knowledge sharing, and awareness. These parameters consistently concern an organization's capability, but cannot be classified into either the structure category, or into the process or IT categories. We discuss these in the next section, in which we develop the conceptual model of inter-organizational ESS usage.

\section{Towards a model of inter-organizational social software usage}

As argued in the course of this paper, adaptions of the original inter-organizational relationships model are necessary to comprehensively cover the determinants of inter-organizational ESS usage. Specifically, the parameters that cannot be classified into the original model's categories prevented us from adopting the model as is. Thus, on the basis of the determinants identified in the interview study, we propose a revised and extended model that specifically considers interorganizational ESS usage's characteristics (see Fig. 4).

The limited number of interviewee references to the environmental type of uncertainty meant we cannot make profound statements concerning this category; consequently, it is dimmed in the graphic above (Fig. 4). We therefore describe task and partnership uncertainties as categories that influence information-processing needs. In terms of the informationprocessing capabilities, we adopted the coordination mechanisms structure, process, and IT. Furthermore, we added a new category to the model, which we named culture. This category comprises the parameters related to cultural aspects that the other categories do not cover. According to the information-processing view, the kind and extent of uncertainties, on the one hand, require an adequate configuration of the coordination mechanisms that, on the other hand, lead to information-processing capabilities.

\section{Information-processing needs}

Information-processing needs are defined as the requirements for inter-organizational ESS usage. Our results show that these requirements can arise from partnership uncertainty and task uncertainty.

The two parameters trust and power characterize the partnership uncertainty category. On the one hand, the extent of the trust each organization has in a partnership is important. The more trustful a relationship, the less the attention that has to be paid to contracts and monitoring. On the other hand, the power-dependence balance affects the perceived uncertainty. If one organization within a partnership wields power, this might have a strong impact on the partnership arrangement. For example, in one case, ESS was used in a buyer-supplier relationship in which the power was not balanced. A strong buyer position can lead to the buyer dictating certain negotiation terms, such as an IT solution's infrastructure. A similarly unbalanced distribution of power can occur if one organization is considerably larger than the other(s) and already has experience with, or even hosts, an own ESS solution. In order to better illustrate their nature, we provided citation examples of each parameter in Fig. 5.

The task uncertainty category covers the two parameters confidentiality and productiveness (please see Fig. 6 for citation examples). The exchange of information and knowledge between the involved parties and mutual content creation are the dominating use cases when working with ESS. Our interviews confirmed that uncertainties emerge from the need to jointly work on tasks. Several interviewees mentioned that ESS differs decisively from prior forms of IOS, such as EDI applications, where the predominant purpose is to exchange data. Our analysis of the interviews allows the conclusion that the confidentiality of mutually created, or provided, content is of particular relevance. Working across organizational
Fig. 5 Citation examples of partnership uncertainty

\begin{tabular}{|c|c|c|}
\hline Trust & I_05: & $\begin{array}{l}\text { "I would say trust is essential for the team spirit of cooperation. A high degree of trust can } \\
\text { reduce the costs of legal issues. If we did not trust each other, the lawyers would be the ones } \\
\text { earning a lot of money" }\end{array}$ \\
\hline Power & I_02: & $\begin{array}{l}\text { "Usually, if the customer is particularly important for our business, we tend to use the solution } \\
\text { he prefers." }\end{array}$ \\
\hline
\end{tabular}


Fig. 6 Citation examples of task uncertainty boundaries on tasks concerning trade or industrial secrets is a highly sensitive issue. These secrets are a large part of uncertainty, thus demanding a great deal from security and legal points of view. Productiveness is another parameter that deserves particular attention. It comprises the extent to which a communication is productive, thus allowing it to successfully cope with a task, rather than being purely conversational. Productive communication should produce real output, i.e., should allow objectives to materialize, for example, when digital content is created and published. In contrast, conversational communication comprises, for example, discussions and idea development.

\section{Information-processing capabilities}

As we learned from our interviews, organizations employ alternate coordination mechanisms that contribute to increasing the information-processing capabilities to cope with these kinds of uncertainty. In the case of inter-organizational ESS usage, we classify these mechanisms into four categories: structure, process, IT, and culture.

In terms of the structure, we emphasize the importance of the dynamics parameter. This represents the extent to which an organization's hierarchy can adapt to different situations. An organization's hierarchy is usually assumed to be robust. However, the classic line organization can appear debilitating when people jointly create content in a bottom-up manner, which often happens with ESS. In order to follow this bottom-up approach, users have to know how dynamic (or not) their organizational structure is. Thus, the transparency of the organizational structure also plays an important role in our model. Resources is another parameter dedicated to this kind of coordinating mechanism. It describes the extent to which positions, for example, for community management or support, are established and funded. Figure 7 provides citation examples of each parameter.
The process category represents the coordination mechanisms, within which the previously defined structural mechanisms are embedded. They affect the extent to which information is freely exchanged between the involved parties. We discovered that the parameter alignment plays an important role, as almost each of the interviewees mentioned it. It describes the extent to which working processes are aligned with the ESS. The role of the parameter privacy is also relevant. Closely related to security issues, which are classified into the $I T$ category, this parameter describes how far employees' privacy concerns are integrated into the existing processes. Since responsibilities for data protection are difficult to define in inter-organizational settings, appropriate working practices have to ensure the user's rights. The parameter support, which represents a large number of interesting statements and is related to the provided resources mentioned previously, reflects the extent of the process-based support in the form of community management and management support. Figure 8 provides citation examples of each parameter.

The IT mechanisms category provides a technological perspective. This category comprises the nature and scope of the ESS in terms of four parameters (please see Fig. 9 for citation examples). Although usability was mentioned in almost all the interviews, it was never rated as very important. However, not only the interviewee statements, but also because usability is actually an ESS characteristic, allow us to conclude that the software should be usable. The parameter malleability is of particular interest: It describes the degree to which ESS is used in an unstructured and an emergent, ad hoc, way. Unlike the structured business processes that traditional IS, such as enterprise resource planning systems, support, ESS does not focus on a particular purpose. Contrary to purpose-specific software, high malleability leads to a wide range of possible ways to appropriate the software (within the context of communication, collaboration, and coordination). The parameter integration characterizes the extent to which ESS is well integrated into the existing IT landscapes. This comprises the
Fig. 7 Citation examples of structure

\begin{tabular}{|lrl|l} 
Dynamics & I_05 & $\begin{array}{l}\text { "The relevant question is whether the organization is able to keep up with the change and can model } \\
\text { its organization chart appropriately." } \\
\text { "You lose leadership structures. Virtual structures cannot be managed by classical management tools. }\end{array}$ \\
Transparency & I_04 & $\begin{array}{l}\text { The chains of command are changing. People have to know about that. They need to note these } \\
\text { changes." } \\
\text { "We have established positions, such as community managers, who contribute to the long-term } \\
\text { success." }\end{array}$
\end{tabular}


Fig. 8 Citation examples of process

\begin{tabular}{|c|c|c|}
\hline Alignment & I_07 & $\begin{array}{l}\text { "Some of our partners have many years of experience in the market. Their processes were established } \\
\text { over time. Each of them has their own idea of how to best conduct these processes. When working on a } \\
\text { joint platform, at least the ones for whom the platform is new have to adjust their processes to the (new) } \\
\text { solution." }\end{array}$ \\
\hline Privacy & I_02 & $\begin{array}{l}\text { "In a business-to-business context, no one is explicitly responsible for privacy concerns. Why should } \\
\text { anyone monitor employees of another company? Still, in order to address the issue appropriately, we } \\
\text { have established privacy issues in our processes. " }\end{array}$ \\
\hline Support & I_04 & $\begin{array}{l}\text { "When questions arise, all users are recommended to make use of various support offers and not make a } \\
\text { big deal of these questions." }\end{array}$ \\
\hline
\end{tabular}

Fig. 9 Citation examples of $I T$

\begin{tabular}{|c|c|c|}
\hline Usability & I_02 & $\begin{array}{l}\text { "You want to have something that doesn't look too old-fashioned, and, at the same time, is very easy } \\
\text { to handle." }\end{array}$ \\
\hline Malleability & I_08 & $\begin{array}{l}\text { "Actually, the platform is supposed to represent real conversations in which you don't have inflexible } \\
\text { and rigid forms to fill out. This is a very important point and has a large influence on how things are } \\
\text { posted, and what kind of content is provided. The tools don't predetermine how to use them." }\end{array}$ \\
\hline Integr & I_04 & $\begin{array}{l}\text { "We want the users not to care about the infrastructure and the products they work with. All they need } \\
\text { to have is a clear desktop with a smart navigation which comprises everything they need for their } \\
\text { work." }\end{array}$ \\
\hline Security & I_02 & $\begin{array}{l}\text { "Do we want an open or a closed solution? Do we want to host it on our servers, on a partner's } \\
\text { infrastructure, or do we prefer a cloud solution? Most people feel queasy if their data is hosted by third } \\
\text { parties, or even abroad." }\end{array}$ \\
\hline
\end{tabular}

customization of the user interface, as well as interfaces to other information systems. The parameter security defines, for example, how open or closed ESS access is. Furthermore, it comprises the platform (the software and hardware) ownership and location. The size, site, and industry of the partners involved impact the security's configuration strongly. For example, one interviewee from the technology sector, where confidential information is exchanged, mentioned that his organization preferred storing all information in its physical networks.

Culture plays an important part as a coordination mechanism. We identified three parameters specifying this category from the interviews: open mindedness is the degree to which an organization is open to new working practices, new technologies, criticism, and even the fostering of a certain loss of control. The parameter knowledge sharing describes how an organization's culture contributes to its members feeling free and willing to communicate their expertise trans-boundary. Awareness is the extent to which the organization's climate helps employees communicate beyond the organizational boundaries, or even across different countries. This implies that not only do different cultures meet, but also that different laws are applied; contributors should therefore be aware of who may be reading what they write. We provide citation examples of culture-related parameters in Fig. 10.

\section{Discussion}

Prior research on IOS and intra-organizational ESS has provided valuable insights that, to some extent, can be transferred to an inter-organizational ESS usage context. However, the specifics of ESS usage require modifications of the original IOS model. The proposed conceptual model provides an overview of the relevant usage determinants concerning the deployment of ESS in an inter-organizational context. It structures the determinants of information processing needs, which arise from uncertainties and information processing capabilities that the four categories of coordinating mechanisms (structure, process, IT, culture) represent. Thereby, these mechanisms represent a set of configuration possibilities depending on the situational uncertainties. Some of the identified parameters are known from the original interorganizational relationships model (Bensaou and Venkatraman 1993). For example, trust and power have also been argued to affect uncertainty about potential opportunistic behavior, thus impacting the need to monitor each other. Furthermore, a significant number of the model's determinants, for example, the cultural parameters (Chai and Kim 2012; Seo and Rietsema 2010), or those concerning security issues (Turban et al. 2011), are well-known from prior
Fig. 10 Citation examples of culture

\begin{tabular}{|c|c|c|}
\hline $\begin{array}{l}\text { Open } \\
\text { mindedness }\end{array}$ & I_01 & $\begin{array}{l}\text { "We are always open to trying out new things. Thereby, it is important to a certain degree to tolerate, } \\
\text { or even foster, people making mistakes." }\end{array}$ \\
\hline $\begin{array}{l}\text { Knowledge } \\
\text { sharing }\end{array}$ & I_02 & $\begin{array}{l}\text { "My company has always required and fostered knowledge sharing. If anyone feels that it would be } \\
\text { better not to communicate what he or she knows, it would be difficult to make full use of all the } \\
\text { possibilities the platform offers regarding supporting successful cooperation." }\end{array}$ \\
\hline Awareness & I_04 & $\begin{array}{l}\text { "We have a problem, because the technical infrastructure doesn't understand the boundaries. Users } \\
\text { of the solution have to know and be aware of these boundaries. Why? A virtual team room can be } \\
\text { full of people from different cultures with different laws. All of these people have to consider the } \\
\text { differences." }\end{array}$ \\
\hline
\end{tabular}


research on intra-organizational ESS. However, there is a crucial difference: These determinants do not only concern one company and its culture; instead, all the involved partners have to meet certain requirements and achieve a minimum of maturity. A single company can influence certain aspects of determinants. For example, employees can jointly work towards a shared understanding of culture that supports and fosters effective ESS usage. Furthermore, functional requirements can be brought in line with the organization's requirements, and internal processes can be aligned with the solution. In contrast, companies involved in an inter-organizational setting have to successfully conduct multifaceted negotiation processes. These negotiation processes comprise all the relevant determinants mentioned above. Ultimately, some of the model's parameters are completely new; they are not described in the original model, nor in prior research on internally used ESS. The parameters that we have identified in our interview study are: confidentiality, productiveness, dynamics, transparency, resources, and awareness. Those determinants, which particularly characterize ESS usage in interorganizational settings, are subsequently discussed.

Negotiations are often not conducted between equal partners. Instead, as mentioned in the discussion on uncertainties, companies might wield their power at this stage of a partnership. Therefore, power does not only depend on the company size, but also on its position in the supply chain (Heide and John 1990). A supplier, for example, may be more likely to accept a buyer's conditions than those of an equal. This is of particular relevance for security issues, such as data authority. Firms wish to control the information systems on their infrastructure (Chatterjee and Ravichandran 2013); powerful firms may even insist on hosting data on their internal networks. Similarly, companies with experience of ESS, or even those operating an own platform, may start dominating. Companies with an edge regarding experience may set certain parameters instead of negotiating these with regard to, for example, the range of functions. In our context, this could lead to (small) companies with less power accepting the conditions that a number of their partners determine, and thus having to adapt their processes to a number of different partnership scenarios.

However, in contrast to many other IS, ESS comprises malleable technologies that offer a wide range of ways to appropriate it (Riemer et al. 2009, 2012). It is hard for organizations to predict how and in what form this kind of software will be used. Rather, users need to experiment with, and make sense of, the platform. Over the last few years, we have increasingly seen emerging use cases that have helped companies support implementation by contributing to the understanding of how ESS can be used internally (e.g., Richter and Riemer 2013). Nevertheless, in an inter-organizational context, ESS has to facilitate heterogeneous daily work practices. All the involved parties need to understand how ESS can and should be used in order to help users embrace this kind of technology. This process may take time, because people only embrace the full potential of ESS when they appropriate it. Thus, there might be new use cases that have not yet been identified. Moreover, the involved companies may already have appropriated different types of ESS, or the same software, but in different ways. Here, it might be necessary to negotiate how the software should be used across boundaries. All this implies that the partners have to be aware that the inter-organizational usage of ESS may require a constant reflection of how it is used and can be used in daily work practices. Given the discursive nature of this approach, it is important to find a tradeoff between maintaining a high degree of flexibility and ensuring that the emerging ways of the software usage converge over time.

\section{Conclusions}

The main objectives of our paper are to contribute to a general understanding of the inter-organizational ESS usage and to identify and explore the relevant usage determinants. Unique to every partnership, and depending on the kind of uncertainties and their extent, one of the main challenges is to find the best configuration of such determinants through multifaceted negotiation processes.

Our study contributes to research and practice. First, we provide a comprehensive overview of relevant determinants for inter-organizational ESS usage. The determinants to be considered when using ESS inter-organizationally are the model's categories and their ESS-specific parameters. Some of them are known from prior studies, but have not yet been applied to an inter-organizational context (e.g., trust, knowledge sharing, security), whereas others were newly identified in our interview study (e.g., confidentiality, productiveness, dynamics). Second, from a theoretical perspective, transferring the IOS's information-processing view to an interorganizational ESS context is a unique contribution. We believe that the proposed model can serve as a framework to empirically examine several research questions, for example, about the correlations between the identified determinants and partnership performance, in the future. Third, we have identified the relevant needs' and capabilities' determinants and, consequently, the differences between using ESS within and across organizational boundaries. From a practical point of view, our model serves as a framework that companies can apply to increase the success probability of engaging in an inter-organizational ESS endeavor. It further offers (potential) users of ESS an overview of the relevant coordination mechanisms.

Some of our study limitations need to be recognized. Our study is explorative in nature and aimed at exploring the field of interest by means of a qualitative approach; consequently, it does not claim to be representative. The role of environmental 
uncertainties is specifically open to discussion. Our interviews provide little evidence related to this category, which could be because it does not play a pivotal role in inter-organizational ESS usage. However, the study's small sample size might be another explanation. Further research should offer valuable clues to the relevance and possible parameters of environmental uncertainties. More studies are also necessary to empirically test the model's relationships, or the possible configurations that ultimately lead to success. Therefore, the identified determinants need to be operationalized. However, IOS studies' general complexity complicates the drawing of valid conclusions. More examination of inter-organizational ESS usage in entire industries and over a longer period (Reimers et al. 2010), or even new approaches to data collection (Reimers et al. 2013), could provide a deeper understanding of the relevant determinants and their relationships. For example, finding answers to the question of how two or more companies' multifaceted negotiation processes can be organized and framed in order to strive for an optimal configuration of the parameters could be exciting and of particular practical relevance. Built on well-founded evidence, for example, from negotiation theory (Raiffa 1982; Ring and Van de Ven 1994), our model could guide future research to address these specific questions.

\section{References}

Aral, S., Dellarocas, C., \& Godes, D. (2013). Social media and business transformation: a framework for research. Information Systems Research, 24(1), 3-13.

Barrett, S. S. (1986). Strategic alternatives and interorganizational system implementations: An overview. Journal of Management Information Systems, 3(3), 5-16.

Barrett, S. S., \& Konsynski, B. (1982). Interorganizational information sharing systems. MIS Quarterly, 112-135.

Bensaou, M., \& Venkatraman, N. (1993). Inter-organizational relationships and information technology: A conceptual synthesis and a research framework: INSEAD.

Bensaou, M., \& Venkatraman, N. (1995). Configurations of interorganizational relationships: a comparison between US and Japanese automakers. Management Science, 41(9), 1471-1492.

Bensaou, M., \& Venkatraman, N. (1996). Inter-organizational relationships and information technology: a conceptual synthesis and a research framework. European Journal of Information Systems, 5(2), 84-91.

Bryman, A., \& Bell, E. (2007). Business research methods. New York: Oxford University Press.

Bughin, J., Byers, A. H., \& Chui, M. (2011). How social technologies are extending the organization. McKinsey Quarterly, 20(11), 1-10.

Cash, J. I., Jr., \& Konsynski, B. R. (1985). IS redraws competitive boundaries. Harvard Business Review, 63(2), 134-142.

Chai, S., \& Kim, M. (2010). What makes bloggers share knowledge? An investigation on the role of trust. International Journal of Information Management, 30(5), 408-415.

Chai, S., \& Kim, M. (2012). A socio-technical approach to knowledge contribution behavior: an empirical investigation of social networking sites users. International Journal of Information Management, 32(2), 118-126.

Chatterjee, D., \& Ravichandran, T. (2013). Governance of interorganizational information systems: a resource dependence perspective. Information Systems Research, 24(2), 261-278.

Choudhury, V. (1997). Strategic choices in the development of interorganizational information systems. Information Systems Research, 8(1), 1.

Chui, M., Manyika, J., Bughin, J., Dobbs, R., Roxburgh, C., Sarrazin, H., \& Westergren, M. (2012). The social economy: Unlocking value and productivity through social technologies. McKinsey Global Institute.

Czepiel, J. A. (1975). Patterns of interorganizational communications and the diffusion of a major technological innovation in a competitive industrial community. Academy of Management Journal, 18(1), 6-24.

Damianos, L. E., Cuomo, D., Griffith, J., Hirst, D. M., \& Smallwood, J. (2007). Exploring the adoption, utility, and social influences of social bookmarking in a corporate environment. In: Proceedings of the 40th Annual Hawaii International Conference on System Sciences (HICSS-40). Waikoloa, Hawaii, USA.

DeLone, W. H., \& McLean, E. R. (2003). The DeLone and McLean model of information systems success: a ten-year update. Journal of Management Information Systems, 19(4), 9-30.

DeLone, W. H., \& McLean, E. R. (1992). Information systems success: the quest for the dependent variable. Information Systems Research, 3(1), 60-95.

Du, H. S., \& Wagner, C. (2006). Weblog success: exploring the role of technology. International Journal of Human-Computer Studies, 64(9), 789-798.

Duane, A. M., \& OReilly, P. (2012). A conceptual stages of growth model for managing an organization's social media business profile (SMBP). In: Proceedings of the 33rd International Conference on Information Systems (ICIS 2012). Orlando, Florida, USA.

Dubé, L., \& Paré, G. (2003). Rigor in information systems positivist case research: current practices, trends, and recommendations. MIS Quarterly, 27(4), 597-636.

Faraj, S., Jarvenpaa, S. L., \& Majchrzak, A. (2011). Knowledge collaboration in online communities. Organization Science, 22(5), 1224 1239

Galbraith, J. R. (1977). Organization design. Reading, Mass.: AddisonWesley.

Gallivan, M. J., \& Depledge, G. (2003). Trust, control and the role of interorganizational systems in electronic partnerships. Information Systems Journal, 13(2), 159-190.

Gelderman, M. (1998). The relation between user satisfaction, usage of information systems and performance. Information and Management, 34(1), 11-18.

Giachetti, R. E. (2004). A framework to review the information integration of the enterprise. International Journal of Production Research, 42(6), 1147-1166.

Goethals, F. G. (2008). Important issues for evaluating interorganizational data integration configurations. Electronic Journal of Information Systems Evaluation, 11(3), 185-196.

Goh, K. Y., Heng, C. S., \& Lin, Z. (2013). Social media brand community and consumer behavior: quantifying the relative impact of user-and marketer-generated content. Information Systems Research, 24(1), 88-107.

Gonzalez, A. (2013). The social side of supply chain management. Supply Chain Management Review, 17(4), 16-21.

Gray, P. H., Parise, S., \& Iyer, B. (2011). Innovation impacts of using social bookmarking systems. MIS Quarterly, 35(3), 629-643.

Hagedoorn, J. (1993). Understanding the rationale of strategic technology partnering: interorganizational modes of cooperation and sectoral differences. Strategic Management Journal, 14(5), 371-385. 
Heide, J. B., \& John, G. (1990). Alliances in industrial purchasing: Tthe determinants of joint action in buyer-supplier relationships. Journal of Marketing Research, 24-36.

Hester, A. J., \& Scott, J. E. (2008). A conceptual model of wiki technology diffusion. In: Proceedings of the 41st Annual Hawaii International Conference on System Sciences (HICSS-41). Big Island, Hawaii, USA.

Hsu, C.-L., \& Lin, J. C.-C. (2008). Acceptance of bog usage: the roles of technology acceptance, social influence and knowledge sharing motivation. Information and Management, 45(1), 65-74.

Hsu, H. Y., \& Tsou, H.-T. (2011). Understanding customer experiences in online blog environments. International Journal of Information Management, 31(6), 510-523.

Huang, K.-Y., \& Güney, S. (2012). Toward a framework of web 2.0driven organizational learning. Communications of AIS, 31, 128152

Ibbott, C. J., \& O'Keefe, R. M. (2004). Trust, planning and benefits in a global interorganizational system. Information Systems Journal, 14(2), 131-152.

Johnston, H. R., \& Vitale, M. A. (1988). Creating competitive advantage with interorganizational information systems. MIS Quarterly, 12(2), $153-165$.

Jussila, J. J., Kärkkäinen, H., \& Aramo-Immonen, H. (2013). Social media utilization in business-to-business relationships of technology industry firms. Computers in Human Behavior.

Kane, G. C., Fichman, R. G., Gallaugher, J., \& Glaser, J. (2009). Community relations 2.0. Harvard Business Review, 87(11), 45-50.

Kane, G. C., Alavi, M., Labianca, G., \& Borgatti, S.P. (2014). What's different about social media networks? A framework and research agenda. MIS Quarterly, forthcoming.

Kaufman, F. (1966). Data systems that cross company boundaries. Harvard Business Review, 44(1), 51-61.

Kiron, D., Palmer, D., Phillips, A., \& Berkman, R. (2013). Social business: Shifting out of first gear. MIT Sloan Management Review. Research Report.

Koroleva, K., Stimac, V., Krasnova, H, \& Kunze, D. (2011). I like it because I ' $\mathrm{m}$ like you - measuring user attitudes towards information on facebook. In: Proceedings of the 32nd International Conference on Information Systems (ICIS 2011). Shanghai, China.

Kügler, M., Smolnik, S., \& Räth, P. (2012). Why don't you use it? Assessing the determinants of enterprise social software usage: A conceptual model integrating innovation diffusion and social capital theories. In: Proceedings of the 33rd International Conference on Information Systems (ICIS 2012). Orlando, Florida, USA.

Kügler, M., Smolnik, S., \& Räth, P. (2013). Determining the factors influencing enterprise social software usage: Development of a measurement instrument for empirical assessment. In: Proceedings of the 46th Annual Hawaii International Conference on System Sciences (HICSS-46). Maui, Hawaii, USA.

Kumar, K., \& Van Dissel, H. G. (1996). Sustainable collaboration: managing conflict and cooperation in interorganizational systems. MIS Quarterly, 20(3), 279-300.

Löhe, J., \& Legner, C. (2010). SOA adoption in business networks: Do service-oriented architectures really advance inter-organizational integration? Electronic Markets, 20(3-4), 181-196.

Lu, X.-H., Huang, L.-H., \& Heng, M. S. H. (2006). Critical success factors of inter-organizational information systems-A case study of Cisco and Xiao Tong in China. Information and Management, 43(3), 395-408.

Majchrzak, A. (2009). Comment: where is the theory in wikis? MIS Quarterly, 33(1), 18-20.

Majchrzak, A., Wagner, C., \& Yates, D. (2013). The impact of shaping on knowledge reuse for organizational improvement with wikis. MIS Quarterly, 37(2), 455-A12.

Mayring, P. (2000). Qualitative content analysis. Forum Quality Social Research, 2(1).
Mouzakitis, S., \& Askounis, D. (2010). A knowledge-based framework for measuring organizational readiness for the adoption of $b 2 b$ integration systems. Information Systems Management, 27(3), 253266.

O'Leary, D. E. (2011). The use of social media in the supply chain: survey and extensions. Intelligent Systems in Accounting, Finance and Management, 18(2/3), 121-144.

Osborn, R. N., \& Hagedoorn, J. (1997). The institutionalization and evolutionary dynamics of interorganizational alliances and networks. The Academy of Management Journal, 40(2), 261-278.

Papadopoulos, T., Stamati, T., \& Nopparuch, P. (2013). Exploring the determinants of knowledge sharing via employee weblogs. International Journal of Information Management, 33(1), 133-146.

Pfaff, C., \& Hasan, H. (2007). Democratising organisational knowledge: The potential of the corporate wiki. In: Proceedings of the 28th International Conference on Information Systems (ICIS 2007). Montreal, Canada.

Potter, W. J., \& Levine-Donnerstein, D. (1999). Rethinking validity and reliability in content analysis. Journal of Applied Communication Research, 27, 258-284.

Prasarnphanich, P., \& Wagner, C. (2009). The role of wiki technology and altruism in collaborative knowledge creation. Journal of Computer Information Systems, 49(4), 33-41.

Rai, A., \& Tang, X. (2010). Leveraging IT capabilities and competitive process capabilities for the management of interorganizational relationship portfolios. Information Systems Research, 21(3), 516-542.

Raiffa, H. (1982). The art and science of negotiation. Cambridge: Harvard University Press.

Räth, P., \& Smolnik, S. (2010). Antecedents and consequences of corporate weblog usage in the intranet: A process perspective. In: Proceedings of the 43rd Annual Hawaii International Conference on System Sciences (HICSS-43). Kauai, Hawaii, USA.

Räth, P., Urbach, N., Smolnik, S., \& Butler, B. S. (2012). Corporate adoption of social computing: a process-based analysis. Journal of Information Technology Case and Application Research, 14(2), 327.

Reimers, K., Johnston, R. B., \& Klein, S. (2010). The difficulty of studying inter-organisational IS phenomena on large scales: critical reflections on a research journey. Electronic Markets, 20(3-4), 229-240.

Reimers, K., Johnston, R. B., Guo, X., Klein, S., Xie, B., \& Li, M. (2013). Novice-based data collection methods for the study of IOIS: practice probes and learning communities. Electronic Markets, 23(4), 285-293.

Richter, A., \& Riemer, K. (2013). Malleable end-user software. Business and Information Systems Engineering, 5(3), 195-197.

Riemer, K., \& Richter, A. (2010). Tweet inside: Microblogging in a corporate context. In: Proceedings of the 23rd Bled eConference. Bled, Slovenia.

Riemer, K., Steinfield, C., \& Vogel, D. (2009). eCollaboration: on the nature and emergence of communication and collaboration technologies. Electronic Markets, 19(4), 181-88.

Riemer K., Overfeld P., Scifleet P. \& Richter, A. (2012). Eliciting the anatomy of technology appropriation processes: A case study in enterprise social media. In: Proceedings of the 20th European Conference on Information Systems (ECIS 2012). Barcelona, Spain.

Riggins, F. J., \& Mukhopadhyay, T. (1994). Interdependent benefits from interorganizational systems: opportunities for business partner reengineering. Journal of Management Information Systems, 11(2), 37-57.

Ring, P. S., \& Van de Ven, A. H. (1994). Developmental processes of cooperative interorganizational relationships. Academy of Management Review, 19(1), 90-118.

Robey, D., Im, G., \& Wareham, J. D. (2008). Theoretical foundations of empirical research on interorganizational systems: assessing past contributions and guiding future directions. Journal of the Association for Information Systems, 9(9), 497-518. 
Saeed, K. A., Malhotra, M. K., \& Grover, V. (2011). Interorganizational system characteristics and supply chain integration: an empirical assessment. Decision Sciences, 42(1), 7-42.

Saldanha, T. J. V., \& Krishnan, M. S. (2012). Organizational adoption of web 2.0 technologies: an empirical analysis. Journal of Organizational Computing and Electronic Commerce, 22(4), 301-333.

Schlagwein, D., Schoder, D., \& Fischbach, K. (2011). Social information systems: Review, framework, and research agenda. In: Proceedings of the 32nd International Conference on Information Systems (ICIS 2011). Shanghai, China.

Schubert, P., \& Legner, C. (2011). B2B integration in global supply chains: an identification of technical integration scenarios. The Journal of Strategic Information Systems, 20(3), 250-267.

Schultze, U., \& Avital, M. (2011). Designing interviews to generate rich data for information systems research. Information and Organization, 21(1), 1-16.

Scott, J. E., \& Hester, A. J. (2007). Organizational Wiki Usage: A Conceptual Model. In: Proceedings of the 28th International Conference on Information Systems (ICIS 2007). Montreal, Canada.

Seddon, P. B. (1997). A respecification and extension of the DeLone and McLean model of IS success. Information Systems Research, 8(3), 240-253.

Seo, D., \& Rietsema, A. (2010). A way to become enterprise 2.0: Beyond web 2.0 tools. In: Proceedings of the 31 st International Conference on Information Systems (ICIS 2010). Saint Louis, Missouri, USA.

Soliman, K. S., \& Janz, B. D. (2004). An exploratory study to identify the critical factors affecting the decision to establish Internet-based interorganizational information systems. Information and Management, 41(6), 697.

Spencer, L., \& Britain, G. (2003). Quality in qualitative evaluation: A framework for assessing research evidence: Government Chief Social Researcher's Office, Cabinet Office.

Steinhueser, M., Smolnik, S., \& Hoppe, U. (2011). Towards a measurement model of corporate social software success-evidences from an exploratory multiple case study. In: Proceedings of the 44th Annual Hawaii International Conference on System Sciences (HICSS-44). Kauai, Hawaii, USA.

Stelzer, D., Fischer, D., \& Nirsberger, I. (2006). A framework for assessing inter-organizational integration of business information systems. International Journal of Interoperability in Business Information Systems, 2, 9-20.

Theotokis, A., \& Doukidis, G. (2009). When adoption brings addiction: A use-diffusion model for social information systems. In: Proceedings of the 30th International Conference on Information Systems (ICIS 2009). Phoenix, Arizona, USA.

Trier, M., \& Richter, A. (2013). "I can simply..." - Theorizing simplicity as a design principle and usage factor. In: Proceedings of the 21st European Conference on Information Systems (ECIS 2013). Utrecht, The Netherlands.

Trier, M., \& Richter, A. (2014). The deep structure of organizational online networking - an actor-oriented case study. Information Systems Journal. doi:10.1111/isj.12047.

Trimi, S., \& Galanxhi-Janaqi, H. (2008). Organisation and employee congruence: a framework for assessing the success of organisational blogs. International Journal of Information Technology and Management, 7(2), 120-133.

Turban, E., Liang, T.-P., \& Wu, S. (2011). A framework for adopting collaboration 2.0 tools for virtual group decision making. Group Decision and Negotiation, 20(2), 137-154.

von Krogh, G. (2012). How does social software change knowledge management? Toward a strategic research agenda. The Journal of Strategic Information Systems, 21(2), 154-164.

Walsham, G. (2006). Doing interpretive research. European Journal of Information Systems, 15(3), 320-330.

Wattal, S., Racherla, P., \& Mandviwalla, M. (2009). Employee adoption of corporate blogs: A quantitative analysis. In: Proceedings of the 42nd Annual Hawaii International Conference on System Sciences (HICSS-42). Big Island, Hawaii, USA.

Wattal, S., Racherla, P., \& Mandviwalla, M. (2010). Network externalities and technology use: a quantitative analysis of intraorganizational blogs. Journal of Management Information Systems, 27(1), 145174.

Webster, J., \& Watson, R. T. (2002). Analyzing the past to prepare for the future: writing a literature review. MIS Quarterly, 26(2), 13-23.

$\mathrm{Wu}, \mathrm{L}$. (2013). Social network effects on productivity and job security: evidence from the adoption of a social networking tool. Information Systems Research, 24(1), 30-51.

Yuthas, K., \& Young, S. T. (1998). Material matters: assessing the effectiveness of materials management IS. Information and Management, 33(3), 115-124. 